\title{
A INTEGRAÇÃO CURRICULAR NO CURSO TÉCNICO EM ELETRÔNICA DO INSTITUTO FEDERAL DO MARANHÃO, CAMPUS ALCÂNTARA
}

\author{
Sônia Pedroni*; Natal Lânia Roque Fernandes \\ E-mail*: soniapedroni@ifma.edu.br \\ *Instituto Federal de Educação, Ciência e Tecnologia do Maranhão - IFMA \\ DOI: $10.15628 /$ rbept.2020.8587
}

Artigo submetido em: 05/2019 e aceito em: 05/2020

\begin{abstract}
RESUMO
O objetivo do presente texto foi refletir sobre a integração curricular nos cursos técnicos integrados ao ensino médio, ofertados pelo IFMA, Campus Alcântara, com base na perspectiva da formação integral. A metodologia utilizada foi análise documental, tendo como fontes documentos legais que orientam a oferta de cursos da Educação Profissional Técnica de nível médio e a Proposta Curricular do Curso Técnico em Eletrônica, do Campus Alcântara. Constatou-se que a proposta curricular explicita a opção pelo currículo integrado e tem uma organização disciplinar que integra os componentes curriculares de formação geral e específica. Embora apresente alguns aspectos contraditórios, pode-se considerar a proposta como importante "travessia" para a formação integral dos trabalhadores.
\end{abstract}

Palavras-Chave: Educação Profissional. Formação integral. Currículo Integrado.

\section{THE CURRICULAR INTEGRATION IN THE TECHNICAL COURSE IN ELECTRONICS OF THE FEDERAL INSTITUTE OF MARANHÃO, CAMPUS ALCÂNTARA}

\begin{abstract}
The purpose of this text was to think about the curricular integration in the technical courses integrated to high school, offered by IFMA, Campus Alcântara, based on the integral formation perspective. The methodology used was documentary analysis, having as sources legal documents that guide the offer of courses in Technical Professional Education at medium level and the Curricular Proposal of the Technical Course in Electronics, from the Alcântara Campus. It was found that the curricular proposal makes explicit the option for the integrated curriculum and has a disciplinary organization that integrates the curricular components of general and specific training. Although it presents some contradictory aspects, the proposal can be considered as an important "crossing" for the integral training of workers.
\end{abstract}

Keywords: Professional Education. Integral formation. Integrated Curriculum.

\section{INTRODUÇÃO}

A educação profissional na forma integrada ao Ensino Médio, amparada nos pressupostos da formação humana integral, por se apoiar na integração dos aspectos científicos, tecnológicos e culturais no processo formativo, Vol. 2 (2020) 
representa para os defensores dessa integração uma possibilidade concreta para a travessia rumo à superação da dualidade estrutural histórica entre formação geral e formação técnica. Com essa compreensão Frigotto, Ciavatta, Ramos (2012) e Moura (2007) ressaltam que a proposta de integração entre formação geral e profissional, tendo o trabalho como princípio educativo e a ciência, a cultura e a tecnologia como categorias indissociáveis, constitui-se condição necessária à "travessia" para uma nova realidade em que todos possam ter acesso a uma educação politécnica.

Os autores em destaque ressaltam também que a proposta de integração, de caráter emancipatório, traz inerentes múltiplos desafios que vão desde a adoção da concepção de formação integrada enquanto projeto social, o compromisso ético e político com tal proposição, a elaboração de uma proposta curricular participativa e sua consequente materialização junto aos sujeitos para o qual se volta. Neste cenário, a formação dos profissionais a serem envolvidos no processo de implementação de uma proposta de integração se apresenta também como parte desses desafios.

O enfrentamento a tais desafios tem se caracterizado por processos de avanços e retrocessos na história da Educação Profissional e Tecnológica. Um dos retrocessos aconteceu na década de 1990, quando os os Centros Federais de Educação, Ciência e Tecnologia - CEFETs, atual Instituto Federal de Educação, Ciência e Tecnologia, se destacavam pela qualidade referenciada a formação técnica integrada ofertada à época. Tal prática foi interrompida pela reforma do ensino profissional vigorada pelo Decreto $\mathrm{n}^{\mathrm{o}}$ 2.208/1997, que ao determinar a educação profissional técnica com estrutura organizativa e curricular própria e independente do ensino médio (BRASIL, 1997), impôs a extinção da integração entre esses segmentos educacionais. Por reeditar a desarticulação, esse dispositivo legal ao tempo que rompeu a equivalência com o ensino médio e priorizou o mercado como foco da profissionalização, abriu espaço para aprofundar a desigualdade e exclusão social.

Para Frigotto, Ciavata e Ramos (2012) o referido Decreto contribuiu para aprofundar a dicotomia entre trabalho e educação, na medida em que além de proibir a pretendida formação integrada, regulamentou formas fragmentadas e aligeiradas de educação profissional, sob a justificativa de atender as alegadas necessidades do mercado. Expressou-se, portanto, o revigorameto da dualidade estrutural, pautada na pedagogia da competência, que afinada às determinações dos organismos financeiros internacionais se colocou à serviço da globalização econômica. A velha controvérsia entre formação geral e formação profissional foi reacendida.

Com a nova configuração política a partir de 2003, no contexto de um governo popular, um movimento que congregou educadores e entidades acadêmicas e científicas passou a reivindicar, em caráter de urgência, uma nova reforma do ensino médio e da educação profissional que sinalizasse para a construção de um novo projeto de educação alinhado com os interesses dos que vivem do trabalho. A revogação do Decreto no 2.208/1997 deu passagem ao Decreto $\mathrm{n}^{\circ}$ 5.154/2004 que apesar de manter determinações do instrumento revogado, trouxe como ganho o restabelecimento da articulação entre o Ensino Médio e a Educação Profissional. 
Dentre outras formas, essa articulação se institui por meio da educação profissional técnica de nível médio integrada ao ensino médio a ser ofertada com uma matrícula única, com vista a assegurar, simultaneamente, o cumprimento das finalidades estabelecidas para a formação geral e as condições de preparação para o exercício de profissões técnicas (BRASIL, 2004). Desde então, a oferta de cursos técnicos integrados tem sido um grande desafio para os Institutos Federais, criados pela Lei ㄲo 11.892/2008. Especialmente pelo fato deste dispositivo legal, nos artigos $7^{\circ}$ e $8^{\circ}$, responsabilizar esta instituição de ofertar no mínimo $50 \%$ das vagas para a Educação Profissional Técnica de Nível Médio, prioritariamente na forma de cursos integrados para estudantes que concluíram ensino fundamental e para jovens e adultos (BRASIL, 2008).

Cabe destacar que essa determinação traz para os Institutos Federais amplos e complexos desafios, dado os diversos problemas que enfrentam. Entre outros aspectos, a formação dos professores da Educação Profissional e Tecnológica - EPT, principalmente os da área técnica, composto em sua maioria por técnicos e engenheiros, historicamente pautada no princípio da racionalidade técnica, assim como, a organização curricular do ensino médio de modelo disciplinar, vivenciada nas escolas públicas brasileira, têm se constituído grandes obstáculos à essa integração.

As pesquisas que tratam da história da Educação Profissional e Tecnológica, dos seus conceitos, fundamentos e princípios, bem como das Diretrizes e Leis que orientam a EP e o ensino médio, têm revelado as dificuldades relativas à essa integração. Com relação aos estudos acerca do currículo integrado na EP, tendo como lócus os micros espaços em que ocorre o planejamento curricular, isto é, os espaços dos diferentes campi dos Institutos Federais, evidenciaram a necessidade de ampliar discussões.

No que se refere ao Instituto Federal de Educação, Ciência e Tecnologia do Maranhão - IFMA, observamos que no Projeto Político Pedagógico Institucional (Resolução CONSUP/IFMA no 076/2016) a instituição assume uma política que reverbera para a integração curricular. Disso decorre a necessidade de pesquisas que se debrucem a discutir a respeito do que é assumido institucionalmente. Reconhecemos, assim, a importância de compreender a formação integrada nos cursos da Educação Profissional Técnica de nível médio do IFMA, tendo como foco o planejamento dos cursos, com o fito de identificar como é pensada e planejada a integração curricular.

Com base na problemática apresentada buscamos elucidar a seguinte questão: como a integração entre os fundamentos científicos e tecnológicos é postana na proposta curricular do Curso Técnico em Eletrônica, na forma integrada ao Ensino Médio do IFMA, Campus Alcântara? Como os princípios da integração são considerados na organização curricular?

Para elucidação de tais questões, objetivamos analisar o Plano do Curso Técnico em Eletrônica, ofertado pelo IFMA, Campus Alcântara, na busca de identificar como está posta na proposta curricular a perspectiva de formação integrada, entendendo que esta sinaliza para a formação integral e que o currículo é concebido como uma construção cultural (SACRISTÁN, 1998). 
Nossa intenção é contribuir com a discussão sobre o Currículo Integrado na Educação Profissional Técnica de Nível Médio, com vista a levantar elementos que se encaminhem para a construção de propostas pedagógicas que tenham, como norte, a formação integral e humana dos sujeitos.

\section{CURRÍCULO INTEGRADO E EDUCAÇÃO PROFISSIONAL}

No campo dos estudos curriculares autores como Moreira; Candau (2003) e Silva (2007) ressaltam a polissemia de significados e sentidos dados ao currículo, os quais são perpassados por diversas orientações teóricas que apontam diferentes formas de organizá-lo e de tratá-lo. É possível identificar que desde as primeiras décadas do século XX até os dias atuais, estudiosos têm construído definições, conceitos e desenhos curriculares, tendo em vista atender à demanda educacional apresentada em cada época ou contribuir com a reflexão e compreensão do processo de desenvolvimento curricular.

Para o presente estudo a respeito de currículo, busca-se as contribuição de Moreira; Candau (2003) para os quais currículo significa um conjunto de práticas pedagógicas com intencionalidade educativas, que envolvem experiências escolares organizadas, a partir dos conhecimentos historicamente produzidos, com o sentido de contribuir para a formação das identidades dos sujeitos. Importa dizer que currículo não pode ser encarado como uma simples relação de conteúdos a serem trabalhados em um curso ou série, pois em síntese significa um documento e processo que constrói identidades específicas, sendo por meio dele que se realizam basicamente as funções da escola como instituição formadora.

Cabe ressaltar que o currículo da Educação Profissional tem se configurado historicamente como um palco de disputas no qual se confrontam projetos educativos embasados em paradigmas divergentes. Isso porque a EP, no decurso de sua história, assenta-se, por um lado, em projetos voltados para a manutenção de uma sociedade excludente e mercadológica, sob a defesa de grupos conservadores; e, por outro lado, em projetos que visam a construção de uma sociedade inclusiva e humanizada, defendidos por um grupo de pensadores progressistas que almejam uma educação que contribua com a transformação da sociedade.

Na perspectiva progressista, acena-se para a educação profissional um projeto educativo que ao articular ciência, tecnologia e cultura sobre uma base unitária contribua para formar pessoas ética e culturalmente elevadas. A educação neste contexto, tendo o trabalho como princípio educativo, é concebida como prática social (RAMOS, 2009) que tem a finalidade de propiciar uma formação integral aos estudantes provenientes da classe trabalhadora. Isso pressupõe a definição de projetos educativos voltados, fundamentalmente, para o processo de humanização, o que requer, segundo Ciavatta (2008), um currículo capaz de propiciar um vínculo entre educação e 
trabalho, condição essencial para promover uma formação sólida, não apenas para a produtividade ${ }^{1}$, mas também para a emancipação.

Ciavatta (2008) ressalta que o currículo crítico e emancipatório na educação profissional deve oportunizar aos estudantes uma formação que lhes propicie sólida formação intelectual e profissional, capaz de levá-los a fazer a leitura ampliada de mundo. Tal currículo deve, portanto, articular a cultura da escola com a cultura do trabalho, sempre visando a formar seres humanos para a liberdade. Portanto, contrário da formação que submete aos ditames do capital, defende a que capacite para a busca por melhores condições de vida e para a luta pela transformação socal.

A integração da Educação Profissional com o Ensino Médio, viabilizada pelo Decreto $n^{\circ}$ 5.154/2004, configura-se como possibilidade para a construção desse currículo crítico e emancipatório, que se coloque no enfrentamento da dualidade histórica entre formação geral e formação profissional, com vistas à formação integral dos sujeitos. Para Ciavatta (2012) tal integração significa conceber a Educação Geral de forma inseparável da Educação Profissional em todos os espaços e níveis em que ocorre a preparação para o trabalho. Portanto, sem desconsiderar que a dicotomia entre trabalho intelectual e trabalho manual é inerente ao modo de produção capitalista, essa proposta de integração refuta essa dicotomia, na medida em que busca incorporar a dimensão intelectual ao trabalho produtivo.

O trabalho é categoria central desta proposta, compreendido como uma atividade ontológica, estruturante dos sujeitos, no qual o ser humano, através de sua ação sobre o meio, modifica a natureza e, ao modificá-la, modifica a si próprio. Sendo assim, o trabalho se constitui elemento central das diferentes dimensões da vida humana, e não reduzido a uma atividade laborativa, na qual vende a força do trabalho em troca de um salário. Com esse entendimento Frigotto (2012, p. 59) esclarece que:

[...] na sua dimensão mais crucial, ele aparece como atividade que responde à produção dos elementos necessários e imperativos à vida biológica dos seres humanos, enquanto seres ou animais evoluídos da natureza. Concomitantemente, porém, responde às necessidades de sua vida cultural, social, estética, simbólica, lúdica e afetiva. (FRIGOTTO, 2012, p. 59)

Ramos (2012) propõe que na organização de uma proposta curricular integradora, tendo o trabalho como princípio educativo, deve-se partir da totalidade social para estruturar os conteúdos que irão compor o currículo, com vista a possibilitar a compreensão da realidade pelos sujeitos. Esses conteúdos

\footnotetext{
${ }^{1}$ Formar para a produtividade não no sentido da exploração do trabalho pelo capital, mas na acepção defendida por Ciavatta (2008) em que toda atividade humana é produtiva, tanto material como imaterial.
}

Vol. 2 (2020) 
não serão percebidos de forma isolada mas, sim, em diálogo com as diversas áreas de conhecimentos.

A autora ressalta, ainda, alguns pressupostos filosóficos que fundamentam a organização curricular. O primeiro é a concepção de ser humano como ser histórico-social que produz conhecimentos à medida em que se relaciona com a natureza, transformando-a e transformando a si próprio nessa relação. O segundo é o princípio de que a realidade concreta se constitui em uma totalidade, síntese de múltiplas relações. Um terceiro princípio, de ordem epistemológica, significa compreender os conhecimentos como produção do pensamento que se apropria das relações estabelecidas na realidade concreta. Isso tem implicações importantes para a construção do currículo, pois a adoção do trabalho como princípio educativo refere-se "[...] a uma formação baseada no processo histórico e ontológico de produção da existência humana". (RAMOS, 2012, p. 120).

O conceito de integração, portanto, requer conceber a educação como uma totalidade social, compreendendo-a a partir das múltiplas mediações históricas. Assim, é capaz de promover a emancipação do ser humano à proporção que garanta ao "[...] adolescente, ao jovem e ao adulto trabalhador o direito a uma formação completa para a leitura do mundo e para a atuação como cidadão, pertencente a um país, integrado dignamente à sua sociedade política". (CIAVATTA, 2012, p. 85).

É importante considerar que para a perspectiva teórica que fundamenta estas discussões, o conhecimento se processa na elaboração da síntese em nível de abstração das relações estabelecidas no concreto, de maneira que as teorias e conceitos são resultados de apreensões elaboradas e formalizadas no plano do pensamento. Isso significa compreender a realidade como uma totalidade, sendo necessário conhecer as partes e as relações que se estabelecem entre elas. Desta forma, uma proposta curricular cuja organização didático-pedagógica se compromete com a formação integral dos sujeitos, fundamentalmente, deverá considerar tais pressupostos. (RAMOS, 2012).

Outro ponto que Ramos (2012) destaca é que a integração curricular pressupõe uma relação orgânica entre os conhecimentos gerais e os específicos da formação profissional. Sendo assim, o desenho curricular que propõe a superação do fazer pedagógico fragmentado, ao tempo que deve embasar-se no trabalho como princípio educativo ${ }^{2}$ deve adotar procedimentos didático-metodológicos que priorizem a interdisciplinaridade como princípio pedagógico.

Para Kuenzer (2007) a interdisciplinaridade se constitui em um diálogo entre diferentes disciplinas, contribuindo de forma recíproca para a análise de um mesmo objeto, sem que haja necessariamente a diluição dos componentes curriculares. Cada disciplina mantém seus métodos, objetos de estudos e sua autonomia. A esse respeito Ramos (2012) alerta que o processo interdisciplinar, contrário à eliminação das disciplinas, requer um constante

\footnotetext{
2 Compreendido como um princípio ético-político e não como uma técnica didática ou metodológica no processo de aprendizagem; trabalho enquanto atividade criadora da existência humana. (FRIGOTTO; CIAVATTA; RAMOS, 2018).
} 
diálogo entre elas, de forma a tornar possível a contribuição das diferentes abordagens para alcançar um olhar global sobre determinado objeto de estudo, promovendo um conhecimento aprofundado e mais dinâmico. Ou seja, permite a reconstrução da totalidade a partir do olhar dos diversos campos da ciência (RAMOS, 2012).

Deste modo, no processo formativo deve ser reforçada a contribuição que cada área científica do currículo traz para a constituição do sentido elucidador dos múltiplos aspectos da realidade humana, no contexto da realidade natural, social e cultural em que se encontram os jovens em formação. A perspectiva interdisciplinar, é uma maneira de olhar, é o meio imprescindível para reconhecer a relevância dos diferentes conteúdos que configurarão o currículo, e que possibilitam ampliar o universo formativo sem abrir mão da especificidade disciplinar dos quais são procedentes.

Esses princípios, considerados fundamentais na proposição de um projeto de educação na perspectiva da formação humana, têm sido ressaltados nas discussões de autores da linha de trabalho e educação e, de certa forma, observados nas legislações educacionais que têm orientado a propositura da integração entre Educação Profissional e Ensino Médio.

Como antes abordado, a possibilidade de integração da Educação Profissional Técnica de Nível Médio e o Ensino Médio previsto pelo Decreto no 5.154/2004, se coloca contrária à dualidade historicamente construída na educação brasileira entre educação propedêutica e educação profissional, na qual a trajetória educacional dos estudantes traz a marca da classe social a qual pertencem. A regulamentação desta proposição, que tem como centralidade o trabalho como princípio educativo e a indissociabilidade entre teoria e prática, foi fundamental para oportunizar às instituições a possibilidade de implementar um projeto unitário de educação.

Estes princípios estão expressos nas Diretrizes Curriculares Nacionais para a Educação Profissional de Nível Médio (Resolução CNE/CEB № 6/2012), os quais se somam a outros tais como: integração entre trabalho, ciência, tecnologia e cultura como base da proposta pedagógica e curricular; a pesquisa como princípio pedagógico; a contextualização, flexibilidade e interdisciplinaridade na utilização de estratégias favoráveis à compreensão de significados e à integração entre a teoria e vivência da prática professional. (BRASIL, 2012).

\section{PERCURSO METODOLÓGICO}

Com base na argumentação de que o uso da análise documental possibilita ao pesquisador reunir muitas informações sobre leis e documentos, dando suporte para a descrição e interpretação do fenômeno sobre o qual se debruça (TRIVIÑOS, 2008) assumimos esta perspectiva de pesquisa. Nesse sentido, a metodologia utilizada na investigação constituiu-se em um estudo descritivo a partir da análise do Plano do Curso Técnico em Eletrônica na forma Integrada ao Ensino Médio, ofertado pelo IFMA, Campus Alcântara. 
O Campus Alcântara oferta Cursos Técnicos em Eletrônica, Hospedagem, Meio Ambiente, Administração, Eletrotécnica e Desenvolvimento de Sistemas, na forma Subsequente ao Ensino Médio e Cursos Técnicos em Eletrônica, Guia de Turismo e Meio Ambiente na forma Integrada ao Ensino Médio. Os cursos de Guia de Turismo e Meio Ambiente também são ofertados na modalidade de Educação de Jovens e Adultos, através do Programa Nacional de Integração da Educação Profissional com a Educação Básica na Modalidade de Educação de Jovens e Adultos - PROEJA.

Optamos por fazer análise do Plano do Curso Técnico em Eletrônica, por ser o que apresenta maior concorrência nos processos seletivos de ingresso, bem como, por ser o curso com maior número de turmas ofertadas. O Curso Técnico em Eletrônica, na forma Integrada ao Ensino Médio oferta, anualmente, 40 vagas desde 0 ano de 2010.

Para análise do Plano do Curso, nos embasamos nos estudos de Benfatti; Leitinho (2013), que apresentam uma proposta de avaliação para o currículo integrado, nos seus âmbitos politico, pedagógico e administrativo, tendo por base os princípios da ética, globalidade, processualidade e contextualização. As referiadas autoras desenvolveram um modelo avaliativo organizado a partir de três eixos estruturantes: prescrição conceitual, organização didático- conceitual e contexto político-conceitual. Para cada eixo, foram criados indicadores de avaliação.

Para a realização da pesquisa, objeto deste artigo, foi feito um recorte metodológico da proposta das autoras, optando por estruturar a análise curricular com base em alguns descritores sugeridos. Assim, optamos pelos descritores: concepção integrada, declarada ou implícita na proposta pedagógica; objetivos integrados e/ou articulados, pertencente ao eixo prescrição conceitual; gestão pedagógica do Currículo Integrado, a qual compõe o eixo contexto político-contextual; metodologia desenvolvida nas situações de aprendizagem e atividades ou projetos integrados desenvolvidos, ambos pertencentes ao eixo organização didático-conceitual.

\section{A INTEGRAÇÃO NO CURRÍCULO DO CURSO TÉCNICO EM ELETRÔNICA}

O Plano do Curso Técnico em Eletrônica foi elaborado por uma Comissão instituída através de Portaria, envolvendo professores e equipe pedagógica. Essa comissão era composta por profissionais, sendo a maioria recém-contratada e sem compreender muito bem a proposta educativa para a educação profissional instituída pelo Decreto ํㅜ․154/2004.

O curso foi aprovado em 2010 e passou por uma reformulação na sua organização curricular original, que resultou na proposta curricular analisada nesse estudo. O Plano do Curso reformulado possui 74 páginas e todos os elementos exigidos pela Resolução CNE/CEB no 6/2012 foram aprovados pelo Conselho Superior do IFMA por meio da Resolução CONSUP/IFMA ํo 066/2015. 
O Plano do Curso tem uma estrutura organizacional, em que primeiramente apresenta a justificativa, os objetivos e o perfil profissional de conclusão. Em seguida, explicita a organização curricular, com a matriz curricular e as ementas de todos os componentes curriculares. Por fim, expõe a sistemática de avaliação, infraestrutura do Campus (incluindo laboratórios e acervo bibliográfico) e o quadro de profissionais necessários para à execução do curso. A análise dos elementos constitutivos do Plano do Curso permitiu tecer algumas considerações, conforme apresentamos a seguir.

\subsection{CONCEPÇÃO E OBJETIVOS DA PROPOSTA CURRICULAR}

A análise dos conceitos e dos objetivos da proposta curricular do Curso Técnico em Eletrônica permitiu perceber que, embora esteja explicito o objetivo de atender à demanda do mercado, a intenção da instituição em formar cidadãos críticos está fortemente demarcada. Os objetivos do curso expressam a intenção da formação de jovens cidadãos, com conhecimentos científicos e tecnológicos que Ihes permitam exercer atividades específicas da área de eletrônica, em condições de produzir conhecimentos "[...] alicerçados em princípios e valores que dignificam o ser humano". (IFMA, 2015, p. 8). Igualmente destacam a preocupação com o desenvolvimento da capacidade crítico-reflexiva, através do estudo dos "fundamentos socioculturais, científicos e tecnológicos, historicamente acumulados, visando preparar os jovens para o exercício da cidadania e sua inserção no trabalho à luz dos valores políticos, sociais e éticos. (IFMA, 2015, p. 8).

Tais objetivos pressupõem uma formação emancipatória que fundamenta a educação profissional, discutida neste trabalho, capaz de assegurar aos trabalhadores a compreensão dos fundamentos científicos e tecnológicos que estão na base da produção humana e lhes possibilite uma inserção digna na sociedade. No entanto, é possível identificar certo distanciamento de uma proposta emancipatória e o alinhamento com a lógica capitalista quando propõe formar profissionais empreendedores autônomos como se observa no perfil profissional "[...] adotar uma postura empreendedora para administrar seu próprio negócio e crescimento profissional". (IFMA, 2015, p. 09). Certa adesão à lógica de transferir para o trabalhador a responsabilidade individual de garantir sua inserção no setor produtivo não nos passa despercebida, o que reforça o entendimento de Santos (2017) quando diz que empreendedorismo empresarial é proposto pela própria legislação como solução para a escola do trabalhador.

\subsection{GESTÃO PEDAGÓGICA}

Em relação à gestão pedagógica, observamos que a proposta curricular propõe a integração entre o Ensino Médio e a formação profissional, utilizando como dispositivo de organização didático-pedagógica o formato modular para 
organização dos componentes curriculares que integram a Matriz Curricular do curso (FIGURA 1).

Figura 1: Quadro sobre a matriz Curricular Curso Técnico em Eletrônica, módulos I, II, III e IV

\begin{tabular}{|l|l|l|l|}
\hline Módulo I & & Módulo II & \\
\hline Língua Portuguesa I & 60 & Língua Portuguesa II & 60 \\
\hline Física I & 60 & Matemática II & 60 \\
\hline Química Geral I & 40 & Física II & 40 \\
\hline Biologia I & 40 & Química Geral II & 40 \\
\hline Geografia I & 40 & Biologia II & 40 \\
\hline História I & 40 & Geografia II & 40 \\
\hline Arte I & 40 & História II & 40 \\
\hline Sociologia I & 40 & Filosofia I & 40 \\
\hline Língua Inglesa I & 40 & Língua Espanhola I & 40 \\
\hline Educação Física I & 40 & Educação Física II & 40 \\
\hline Informática & 40 & Empreendedorismo & 60 \\
\hline Higiene e Seg. no Trabalho & 40 & Algoritmo e Ling. de Programação & 80 \\
\hline Eletricidade & 40 & Análise de Circuito CC & 40 \\
\hline Subtotal & 80 & Desenho Técnico & 660 \\
\hline Módulo III & 640 & Subtotal & 60 \\
\hline Língua Portuguesa III & & Módulo IV & 60 \\
\hline Matemática III & 60 & Língua Portuguesa IV & 40 \\
\hline Física III & 60 & Matemática IV & 40 \\
\hline Físico-Química I & 40 & Física IV & 40 \\
\hline Biologia III & 40 & Físico-Química II & 40 \\
\hline Geografia III & 40 & Biologia IV & 40 \\
\hline História III & 40 & Geografia IV & 40 \\
\hline Arte II & 40 & História IV & 40 \\
\hline Sociologia II & 40 & Filosofia II & 40 \\
\hline Língua Inglesa II & 40 & Língua Inglesa III & 40 \\
\hline Língua Espanhola II & 40 & Língua Espanhola III & 60 \\
\hline Educação Física III & 40 & Educação Física IV & 60 \\
\hline Análise de Circuito CA & 40 & Automação e CLP & 60 \\
\hline Eletrônica Digital & 60 & Eletrônica Analógica I & 660 \\
\hline Subtotal & 60 & Instrumentação Eletrônica & \\
\hline & 640 & Subtotal & \\
\hline
\end{tabular}

Fonte: Plano do Curso Técnico em Eletrônica, IFMA Campus Alcântara

A matriz possui seis módulos a serem desenvolvidos em três anos letivos, com o tempo mínimo para integralização curricular de três ano e o máximo de seis anos, contando com uma carga horária total de 3.960 horas aulas de cinquenta minutos, distribuídos nos módulos conforme as Figuras 1 e Figura 2. 
Figura 2: Quadro sobre a matriz Curricular Curso Técnico em Eletrônica módulos V e VI

\begin{tabular}{|c|c|c|c|}
\hline \multicolumn{2}{|l|}{ Módulo V } & \multicolumn{2}{|l|}{ Módulo VI } \\
\hline Língua Portuguesa V & 60 & Língua Portuguesa VI & 60 \\
\hline Matemática V & 60 & Matemática VI & 60 \\
\hline Física V & 40 & Física VI & 40 \\
\hline Química Orgânica I & 40 & Química Orgânica II & 40 \\
\hline Biologia V & 40 & Biologia VI & 40 \\
\hline Geografia V & 40 & Geografia VI & 40 \\
\hline História V & 40 & História VI & 40 \\
\hline Arte III & 40 & Filosofia III & 40 \\
\hline Sociologia III & 40 & Educação Física VI & 40 \\
\hline Educação Física V & 40 & Laboratório de Eletrônica & 60 \\
\hline Eletrônica Analógica II & 60 & Eletrônica de Potência & 60 \\
\hline Instalações Elétricas & 60 & Mont. e Manut. de Computadores & 60 \\
\hline Microcontroladores & 80 & Telecomunicações & 40 \\
\hline Redes de Computadores & 60 & Segurança em Eletricidade & 40 \\
\hline Subtotal & 700 & Subtotal & 660 \\
\hline Total de Horas Aula & & 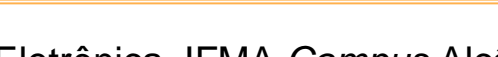 & 3960 \\
\hline
\end{tabular}

Embora conceptualmente a proposta seja integradora, na matriz curricular expressam-se elementos que destoam dessa concepção pois ao tempo que se projeta numa perspectiva integradora a organização curricular foi pensada no formato modular. Esse formato advém do Decreto no 2.208/1997 que determinava a estruturação do currículo em disciplinas, podendo ser agrupadas por módulos que poderiam ter caráter de terminalidade e encaminhar para uma certificação de qualificação profissional, dando um carater fragmentado ao processo formativo.

Podemos inferir que o formato modular previsto no Decreto traduz o aligeiramento da formação embasado na ideia de que vai propiciar uma inserção mais rápida dos alunos no mercado de trabalho e atender as necessidades do setor produtivo por profissionais qualificados. Além de contrapor-se à concepção de formação proposta no projeto institucional, desconsidera que a qualificação por si só não tem o poder de assegurar vagas no mercado de trabalho cada vez mais restritivo. Cabe lembrar que a inserção nos postos de trabalho depende de critérios diversos compactuados nas relações de trabalho mais amplas, nas quais a qualificação do trabalhador é apenas uma das faces, a qual vai depender das demandas e exigências que afloram na lógica de acumulação capitalista.

O desenho curricular do curso propõe uma superação do fazer pedagógico fragmentado pela adoção de procedimentos didáticometodológicos, que priorizem a interdisciplinaridade como princípio norteador, como está expresso no item organização curricular 
(...) uma prática pedagógica voltada à concepção de um currículo integrado, que não se fragmenta sob o subterfúgio da disciplinaridade curricular. Disciplinaridade esta que não perde sua identidade e sua especificidade pela natureza de cada disciplina e pelo seu objeto de estudo, visto que se encontra concebida como dispositivo didático-pedagógico e não como lócus de um determinado campo de conhecimento. (IFMA, 2015, p.11).

Neste aspecto, guarda coerência com os fundamentos que dão base a uma proposta integradora, pois a integração curricular pressupõe uma relação entre os conhecimentos para além da separação entre formação geral e formação específica.

O tratamento pedagógico exige a compreensão da realidade como uma totalidade social e a integração das dimensões que estruturam a prática social, como o trabalho, a ciência, e a cultura, de maneira que o processo de ensino e aprendizagem favoreça a apreensão de conceitos como sistemas de relações da totalidade concreta que se quer explicar (RAMOS, 2009).

\subsection{PROPOSTAS METODOLÓGICAS E PROJETOS INTEGRADORES}

O uso da interdisciplinaridade promove a reunificação do saber, organizado em áreas de conhecimentos e impõe-se como uma necessidade para a concretização de uma proposta educativa voltada para à formação de sujeitos históricos. Ramos (2009) acentua que ela permite a reconstituição da totalidade pela relação entre conceitos, originados nos diversos campos da ciência, representados, pedagogicamente, por disciplinas.

Neste sentido, a referida autora propõe que sejam consideradas as múltiplas dimensões que compõem a totalidade de determinado conteúdo: sócio-histórico-cultural, físico-ambiental, econômico-produtiva e técnicoorganizacional. Tais dimensões devem ser exploradas pelas diferentes áreas de conhecimento, a partir de um processo de produção e/ou fenômeno social específico que se situa no centro da atividade pedagógica. (RAMOS, 2009).

Vale ressaltar que interdisciplinaridade é fundamental no processo de integração, mas para isso é necessário que os sujeitos envolvidos no processo se disponibilizem a fazer o planejamento na lógica interdisciplinar, o que requer formação e disposição dos profissionais para assumir essa tarefa.

A proposta curricular do Curso Técnico em eletrônica parte do princípio de que a integração entre a Educação Básica e a Educação Profissional exige uma organização curricular que expresse princípios pedagógicos que convirjam nesta direção:

[...] A integração entre a Educação Básica com a Educação Profissional somente se efetivará pela superação do fazer 
pedagógico descontextualizado, fragmentado; pelo entendimento que o conhecimento constitui um conjunto orgânico; pela adoção de procedimentos didático-metodológicos que contemplem a interdisciplinaridade, a contextualização, a estética da sensibilidade, política de igualdade e a ética da identidade como princípios norteadores do processo de ensino e aprendizagem (IFMA, 2015, p. 11).

Como é possível observar, a organização curricular está assentada em elementos fundamentais para a materialização da integração: a contextualização e a pesquisa como princípios pedagógicos, expressos no documento

O Curso Técnico em Eletrônica, na forma integrada ao Ensino Médio, apresenta uma proposta curricular pautada nos princípios da interdisciplinaridade e contextualização das bases tecnológicas, a fim de concretizar a integração dos componentes curriculares nas dimensões científicas, tecnológicas e técnico-operativas (IFMA, 2015, p. 3)

Em relação à contextualização, esta contribui para fazer a ponte entre os conhecimentos científicos com aqueles advindos das experiências de vidas dos estudantes, seja no contexto sociocultural, seja as ações ou processo de trabalho proporcionando superar a separação entre conhecimentos científicos e a prática social dos estudantes. Desta forma, a contextualização se constitui em um elemento importantíssimo para a efetivação da unidade entre teoria e prática (MACHADO, 2010).

Outra dimensão importante nesse processo se refere à pesquisa enquanto procedimento metodológico. As atividades de pesquisa têm papel especial na integração curricular, sendo enfocadas na proposta como parte da ação docente. No documento esta preocupação é evidenciada, sobretudo, ao trazer registrado que "[...] destaque especial será dado ao uso da pesquisa como procedimento de ensino e aprendizagem, cujo procedimento deverá integrar o fazer pedagógico do corpo docente, respeitando a especificidade de cada disciplina". (IFMA, 2015, p. 11).

Outro aspecto que observamos na organização curricular da proposta estudada é que esta ressalta procedimentos metodológicos que valorizam o uso de diversos dispositivos didáticos, que traduzem um processo de ensino e aprendizagem ativo e interativo, no qual os estudantes se constituem sujeitos na construção do próprio conhecimento. Isso se evidencia quando traz registrado a opção pela aplicação "[...] dos conhecimentos em situações reais, em produções inovadoras, em ações que encaminhem à resolução de problemas" (IFMA, 2015, p. 11). A esse respeito, Ramos (2010, p. 80) ressalta:

[...] a importância de que as ações pedagógicas estejam alinhadas com os processos de trabalho dos estudantes pela proposição de desafios, problemas e/ou projetos, desencadeando, por parte do 
aluno, ações resolutivas, incluindo as de pesquisa e estudo de situações, elaboração de projetos de intervenção.

Com esse mesmo entendimento, Moura (2007) sugere a implementação de projetos integradores como potencializador da concretização do princípio da interdisciplinaridade. Ressalta que por meio de projetos existe a possibilidade de promover a articulação dos saberes dos diferentes campos da ciência, organizados em componentes curriculares. $E$ que a pesquisa além de potencializar a formação da autonomia intelectual dos estudantes contribui para fomentar o desenvolvimento de atitudes de cidadania, solidariedade e responsabilidade social. O referido autor chama ainda a atenção para o fato de que os projetos devem estar vinculados à busca de soluções para problemáticas locais e regionais, tendo em vista os contextos nacional e mundial.

Cabe observar que ainda que a proposta expresse elementos que os autores discutiram acima, não observamos na matriz curricular do curso analisado algum componente curricular voltado especificamente para o desenvolvimento de projetos integradores. Temos claro que isso não inviabiliza que a interdisciplinaridade ocorra, pois o diálogo entre as diferentes disciplinas pode acontecer de diversas formas e desenhos metodológicos.

\section{CONSIDERAÇÕES FINAIS}

Constatamos na análise da proposta curricular do curso investigado que a mesma foi elaborada com o propósito de construir uma proposta curricular que viabilize a articulação entre os conhecimentos considerados gerais e específicos, o que significa um passo importante para o enfrentamento da dualidade histórica entre formação propedêutica e profissional.

Neste Plano estão presentes elementos importantes para 0 desenvolvimento de uma proposta integrada como a interdisciplinaridade como princípio pedagógico, assim como, a contextualização e a pesquisa como princípios pedagógicos. No entanto, não se percebe na proposta curricular uma orientação clara de como a interdisciplinaridade deve ocorrer, pois ela está posta, mas de forma genérica.

Outro elemento fundamental nesse processo de formação do trabalhador na perspectiva da integralidade é ter o trabalho como um princípio educativo. Embora o Plano do Curso não aponte textualmente, percebemos que ele se faz presente quando é proposto concretizar o processo educativo que sintetize o domínio teórico e prático dos conhecimentos, pois está implícita a compreensão de que é através do trabalho que o ser humano se humaniza e através da unidade entre educação e trabalho que ele se constitui. 
Vale ressaltar que embora as disciplinas estejam organizadas de forma modular, exigindo uma reflexão por parte dos sujeitos do processo, tendo em vista os princípios basilares da integração, observamos que os conhecimentos gerais e específicos estão garantidos em todos os módulos. Portanto, podemos inferir que a proposta representa um esforço no sentido de propiciar aos estudantes os fundamentos científicos e tecnológicos que estão na base dos processos produtivos modernos. O desafio que busca assumir, ainda que limites se interponham, é de uma formação que capacite não apenas para desenvolver uma profissão técnica, mas que vá além, que propicie ao estudante condições para analisar criticamente as relações socioeconômicas, refletir e agir conscientemente na sociedade.

Em síntese, temos o entendimento de que a riqueza dos dados que conseguimos apreender nos permite conclusões provisórias e sem o olhar do todo que compõe a dinâmica do curso analisado. Reconhecemos que embora a proposta pedagógica de um curso seja fundamental para a concretização dos escopos estabelecidos, não é suficiente, pois o currículo em ação envolve práticas reais, dentro de um contexto social que nem sempre possibilita o alcance do planejamento. Dessa forma, a análise do Plano do Curso não nos permite fazer inferências sobre a prática curricular, pois requer outros olhares investigativos.

Para o momento, consideramos que por contemplar os aspectos pontuados pelas diretrizes curriculars de 2012 e defendidos pela literatura específica do currículo integrado, o Plano do Curso sinaliza, ainda que com limites, possibilidades de implementação de um currículo integrado na perspectiva compromissada, ética e politicamente com os trabalhadores.

\section{REFERÊNCIAS}

BENFANTTI, X. D.; LEITINHO, M. C. Que tal começarmos pela avaliação? Uma proposta de avaliação para os currículos do ensino médio integrado. In: HOLANDA, Patrícia H. C; LEITINHO, Meirecele C; CUNHA, Gregório M. da (Org.). A avaliação curricular iluminando os caminhos da Educação Profissional. Fortaleza: Edições UFC, 2013.

BRASIL. Decreto oㅜ 2.208/1997. Regulamenta o $\S^{\circ}$ do art. 36 e os artigos 39 a 42 da Lei 9.394, de 20 de dezembro de 1996, que estabelece as diretrizes e bases da educação nacional. Brasília, 1996. Disponível em:

http://www.planalto.gov.br/ccivil 03/decreto/D2208.htm. Acesso em: 15 set. 2017.

BRASIL. Decreto $n^{\circ} 5.154 / 2004$. Regulamenta o $\S 2^{\circ}$ do art. 36 e os arts. 39 a 41 da Lei no 9.394, de 20 de dezembro de 1996, que estabelece as diretrizes e bases da educação nacional, e dá outras providências. Disponível em: http://www.planalto.gov.br/ccivil 03/ ato2004-2006/2004/decreto/d5154.htm. Acesso em: 15 set. 2017. 
BRASIL. Lei de Diretrizes e Bases da Educação Nacional. Lei nº. 9.394, de 20 de dezembro de 1996. Estabelece as diretrizes e bases da educação nacional. Presidência da República Casa Civil. Brasília, DF, 1996. Disponível em: http://www.planalto.gov.br/Ccivil03/leis/L9394.htm. Acesso em: 15 set. 2017.

BRASIL. Lei no 11.892 de 29 de dezembro de 2008, que institui a Rede Federal de Educação Profissional, Científica e Tecnológica, cria os Institutos Federais de Educação, Ciência e Tecnologia, e dá outras providências. Brasília, DF, 2008.

BRASIL. Resolução CNE/CEB n 6, de 20 de setembro de 2012. Define Diretrizes Curriculares Nacionais para a Educação Profissional Técnica de Nível Médio. Diário Oficial da União: seção 1, Brasília, DF, 21 de setembro de 2012, p. 22. Disponível em:

http://portal.mec.gov.br/com docman\&view=download\&alias=11663-rceb00612-pdf\&category slug=setembro-2012-pdf\&ltemid=30192. Acesso em: 15 set. 2017.

CIAVATTA, M. Formação de professores para educação profissional e tecnológica. Brasília: Instituto Nacional de Estudos e Pesquisas Educacionais Anísio Teixeira, 2008, p 17-40.

CIAVATTA, M. A formação integrada: a escola e o trabalho como lugares de memória e de identidade. In FRIGOTTO, Gaudêncio; CIAVATTA, Maria; RAMOS, Marise (org.). Ensino Médio Integrado: concepção e contradições. 3. ed. São Paulo: Cortez, 2012.

FRIGOTTO, G. Concepções e mudanças no mundo do trabalho e o ensino médio. In FRIGOTTO, G; CIAVATTA, M; RAMOS, M. (Orgs.). Ensino médio Integrado: concepções e contradições. 3. ed. São Paulo: Cortez, 2012.

FRIGOTTO, G; CIAVATTA, M; RAMOS, M. A gênese do Decreto n. 5.154/2004: um debate no contexto controverso da democracia restrita. In: FRIGOTTO, G; CIAVATTA, M; RAMOS, M (org.). Ensino Médio Integrado: concepção e contradições. 3. ed. São Paulo: Cortez, 2012.

FRIGOTTO, G; CIAVATTA, M; RAMOS, M. O trabalho como princípio educativo no projeto de educação integral de trabalhadores- Excertos. 2005. Disponível em:

http://redeescoladegoverno.re.gov.br/upload/13922158390\%20TRABALHO\% 20COMO\%20PRINC\%\%C3\%8DPIO\%20EDUCATIVO\%20NO\%20PROJETO. pdf. Acesso em: 05 fev. 2018.

INSTITUTO FEDERAL DO MARANHÃO. Plano de Curso Técnico em Eletrônica na forma Subsequente ao Ensino Médio. Alcântara: 2015.

INSTITUTO FEDERAL DO MARANHÃO. Projeto Pedagógico Institucional. Aprovado pela Resolução CONSUP/IFMA no 076/2016. São Luís: [s.n], 2016. Disponível em: https://portal.ifma.edu.br/projeto-pedagogico-institucional-ppi/. Acesso em: 05 fev. 2018.

KUENZER, A. Z. Ensino Médio: construindo uma proposta para os que vivem do trabalho. 5. ed. São Paulo: Cortez, 2007. 
MACHADO, L. Ensino Médio e Técnico com Currículos Integrados: propostas de ação didática para uma relação não fantasiosa. In: MOLL, J. Educação profissional e tecnológica no Brasil contemporâneo: desafios, tensões e possibilidades. Porto Alegre: Artmed, 2010.

MOREIRA, A. F. B; CANDAU, V. M. Educação escolar e cultura(as): construindo caminhos. Revista Brasileira de Educação, n. 23, p. 156-168, maio/ago. 2003.

MOURA, D. H. Educação Básica e Educação Profissional e Tecnológica: dualidade histórica e perspectivas de integração. Holos, Ano 23, Vol. 2, 2007.

RAMOS, M. Concepção do Ensino Médio Integrado. In: ARAÚJO, R; TEODORO, E. (Org.). Ensino Médio Integrado no Pará como Política Pública. Belém: SEDUC-PA, 2009, v., p. 144-182.

RAMOS, M. Implicações Políticas e Pedagógicas da EJA integrada à Educação Profissional. Educação \& Realidade. Ano jan/abr, 2010. Disponível em http://www.scielo.br/pdf/es/v31n111/v31n111a09.pdf. Acesso em: 14 abr. 2019.

RAMOS, M. Possibilidades e desafios na organização do currículo integrado. In: FRIGOTTO, Gaudêncio; CIAVATTA, Maria; RAMOS, Marise (org.). Ensino Médio Integrado: concepção e contradições. 3. ed. São Paulo: Cortez, 2012.

SACRISTÁN, J. Gimeno. O currículo: uma reflexão sobre a prática. 3. ed. Porto Alegre: ArtMed, 1998.

SANTOS, D. Educação e precarização profissionalizante: crítica à integração da escola com o mercado. São Paulo: Instituto Lukács, 2017. SILVA, T. T. Documentos de identidade: uma introdução às teorias do currículo. 2. ed. Belo Horizonte: Autêntica, 2007.

TRIVIÑOS, A. Introdução à pesquisa em ciências sociais: a pesquisa qualitativa em educação. São Paulo: Atlas, 2008. 